\title{
Maternal Influences and Intervention Strategies on the Development of Food Allergy in Offspring
}

\author{
Lefei Jiao ${ }^{1,2}$, Chien-Wen Su ${ }^{2 *}$, Tinglan $\mathrm{Cao}^{3}$, Shasha Zheng ${ }^{4}$, W. Allan Walker ${ }^{2}$ \\ and Hai Ning Shi ${ }^{2 *}$ \\ 1 School of Marine Sciences, Ningbo University, Ningbo, China, ${ }^{2}$ Mucosal Immunology and Biology Research Center, \\ Massachusetts General Hospital and Harvard Medical School, Charlestown, MA, United States, ${ }^{3}$ Laboratory for Lipid \\ Medicine and Technology, Massachusetts General Hospital and Harvard Medical School, Charlestown, MA, United States, \\ ${ }^{4}$ Department of Nutrition, California Baptist University, Riverside, CA, United States
}

OPEN ACCESS

Edited by:

Harry Wichers,

Wageningen University and Research,

Netherlands

Reviewed by:

Marloes Van Splunter,

Wageningen University and Research,

Netherlands

Youcef Shahali,

Centre Hospitalier Universitaire de

Besançon, France

${ }^{*}$ Correspondence:

Chien-Wen Su

CSU2@mgh.harvard.edu

Hai Ning Shi

shiha@helix.mgh.harvard.edu

Specialty section: This article was submitted to

Nutritional Immunology,

a section of the journal

Frontiers in Immunology

Received: 17 November 2021 Accepted: 01 February 2022

Published: 23 February 2022

Citation:

Jiao L, Su C-W, Cao T, Zheng S,

Walker WA and Shi HN (2022)

Maternal Influences and Intervention

Strategies on the Development of

Food Allergy in Offspring.

Front. Immunol. 13:817062.

doi: 10.3389/fimmu.2022.817062
Food allergies and other immune-mediated diseases have become serious health concerns amongst infants and children in developed and developing countries. The absence of available cures limits disease management to allergen avoidance and symptomatic treatments. Research has suggested that the presence of maternal food allergies may expose the offspring to genetic predisposition, making them more susceptible to allergen sensitization. The following review has focused on epidemiologic studies regarding maternal influences of proneness to develop food allergy in offspring. The search strategy was "food allergy OR maternal effects OR offspring OR prevention". A systematically search from PubMed/MEDLINE, Science Direct and Google Scholar was conducted. Specifically, it discussed the effects of maternal immunity, microbiota, breastfeeding, genotype and allergy exposure on the development of food allergy in offspring. In addition, several commonly utilized prenatal and postpartum strategies to reduce food allergy proneness were presented, including early diagnosis of high-risk infants and various dietary interventions.

Keywords: maternal immunity, maternal microbiota, high-risk infants, food allergy, maternal effect, intervention strategies

\section{INTRODUCTION}

The term "allergy" describes an adverse immune response initiated by the host's immune system upon exposure to a given substance that is generally harmless in the environment. Statistical analysis has shown that allergen-induced food allergies affect approximately $2.5 \%$ (ranging from $1 \%$ to $10 \%$ ) of the world's general population (1-3). Over the past several decades, food allergy has emerged unexpectedly as a "second wave" of the allergy epidemic, with an increasing number of infants and children afflicted with the disease from developing and developed countries worldwide (4-6). The prevalence of food-challenge-defined allergy to cow's milk, egg, wheat, soy, peanut, tree nuts, fish, and shellfish was around $0.6 \%, 0.2 \%, 0.1 \%, 0.3 \%, 0.2 \%, 0.5 \%, 0.1 \%$ and $0.1 \%$ in Europe (according to 
the published paper from 2000-2012) (7). Research estimates that the food allergy currently affects $5-8 \%$ of the United States population, and the prevalence of food allergy in young children could grow as rapidly as $1 \%$ in a decade (8), while that of preschool children in developed and developing countries were as high as $10 \%$ (Australia) and $7 \%$ (China), respectively (proven by the oral food challenge test) (2). Throughout the years, accumulating evidence from epidemiological, in vivo, and in vitro experimentation has shed light on the possibility that infants with an atopic family history are genetically predisposed to allergies, especially those born from actively atopic mothers $(9,10)$. 12\% of children with no family history of allergy, $30 \%$ to $50 \%$ of children with a single parental allergy and $60 \%$ to $80 \%$ of children with biparental allergies will develop allergic disease (11). In a population-based study of 5,276 oneyear-old infants, children meeting the current definition of "high risk" for allergic disease (family members with a history of any allergic disease) showed an increase in food allergy compared to those with no family history of allergic disease (12). A possible explanation for this, supplementary to genetic similarity, is the individualized environment each mother provides for the infant during gestation and breastfeeding $(13,14)$. Therefore, a thorough understanding of the underlying mechanisms that mediate maternal influence to develop food allergy in children is critical to developing prevention and treatment strategies for allergic reactions and similar inflammatory diseases (Figure 1).

\section{FOOD ALLERGY}

Typically, food allergens are either naturally occurring proteins or chemical haptens, which are small molecules that elicit immunological responses upon attachment to a larger carrier molecule and host immune recognition (15). Although some found in fruits and vegetables are only allergenic when the product is raw, most can persist through heat and acid treatment, such as during cooking and digestion. Out of the 170 potentially allergenic foods, only several are responsible for approximately $90 \%$ of all allergic reactions, with variations amongst different demographic groups and geographic locations $(15,16)$. Specifically, in the United States, foodspecific immunoglobulin E (IgE) sensitization is commonly induced by milk, eggs, nuts, wheat, soy, and fish $(7,17)$. Symptoms of food allergy in babies can manifest as respiratory symptoms such as sneezing and runny nose, skin symptoms such as redness and hives, and intestinal symptoms such as constipation, flatulence and vomiting. The prevalence of food allergy is highest during early childhood, from infancy to toddler phase, and decreases slightly with age $(18,19)$. In cases where diversely sourced allergens share structural or sequential similarities, a process known as cross-reactivity can occur and elicit unexpected downstream effects. Still, the possibility of its occurrence depends highly on the type of food source where the allergen derives (20).

Based on the current understanding of the immunological mechanisms involved, the scientific community accepts that food allergies encompass IgE-mediated, non-IgE mediated, or a combination of both responses (21). IgE-mediated responses are the best-characterized amongst the few and involve the expression of antibodies known as IgE (22). Upon initial allergen exposure, plasma cells produce food-specific IgE from differentiated allergen-specific B lymphocytes that bind to tissue mast cells and blood basophils to induce allergic sensitization. During later allergen exposures, antigenic proteins can bind and cross-link with the surface-bound IgE, triggering the release of symptom-causing mediators, such as histamine and leukotrienes. Additionally, clinical presentations of the skin, gastrointestinal tract, and respiratory tract may appear as little as two hours of food ingestion (2).

On the other hand, non-IgE mediated, or cell-mediated reactions typically involve delayed-onset symptoms that occur approximately 4 to 28 hours after food ingestion (23). These reactions may exacerbate more severe conditions, such as protein-induced enterocolitis syndrome, allergic proctocolitis, or allergic contact dermatitis if left untreated. Despite the poor clinical and scientific definition of non-IgE mediated allergic reactions, evidence suggests $\mathrm{T}$-cell involvement in its molecular mechanism.

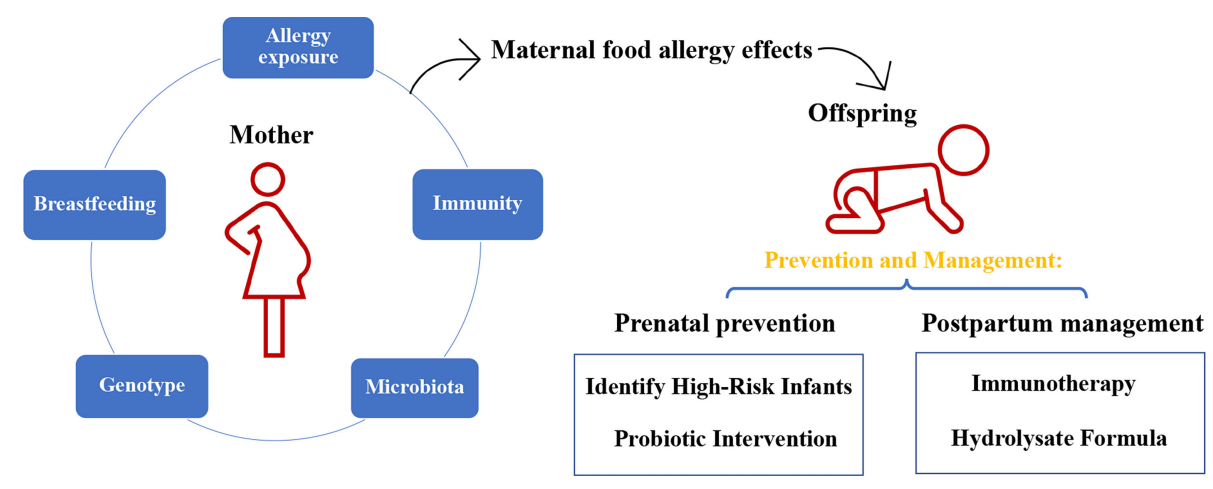

FIGURE 1 | The impact of maternal food allergy on offspring and the method of prevention and management. 


\section{INFLUENCE OF MATERNAL IMMUNITY}

From a genetic perspective, parental phenotype, precisely the maternal phenotype, is known to influence the offspring's inheritance of atopic disease. With that in mind, a deeper understanding of the mechanisms underlying the influence of maternal immunity on the attenuation or exacerbation of offspring disease development is critical to the advancement of prevention strategies against atopic diseases.

A well-balanced maternal immune system will not only actively eliminate potentially harmful microbial stimuli, but also provide protective tolerance for the fetus. Infections during gestation profoundly influence the immunological environment provided by the mother, which then, in turn, affects offspring immunity through regulation of the Th1/Th2 cytokine profile and fetal-maternal immune transfer. In utero, this process occurs via the placenta and is subject to regulation by the placental barrier, which comprises of the tissue layers separating the maternal and fetal circulation systems. The neonatal $F c$ receptor $(\mathrm{FcRn})$ on placental macrophages transports immunoglobulin $\mathrm{G}(\operatorname{IgG})$, the only antibody that can cross the placenta, via the syncytiotrophoblast (24-26). Among the four subtypes of IgG (IgG1, IgG2, IgG3, and IgG4), IgG4 associates closer with IgE during allergic reactions, given that allergen-specific IgG4/IgE ratios are significantly higher in allergy-tolerant individuals than allergy-prone individuals (27). The logic behind this observation is the fact that the non-atopic mother produces abundant IgG1 and IgG3 antibodies that are transported across the placenta to protect the fetus. In contrast, atopic mothers tend to produce IgE and IgG4 antibodies that are unable to cross the syncytiotrophoblast. Also, the newborn may be primed for allergic sensitization and develop early symptoms if fetal IgE is insufficiently downregulated by the lower levels of IgG1 and IgG3 produced by the mother.

Despite the lack of a complete understanding regarding the role of maternal allergen transfer in the development of offspring allergenicity, the most commonly postulated theory is that allergens can be transferred from the mother to fetus in the form of an IgG/allergen immune complex (28). In this case, fetal exposure to these antigens in the environment of the uterus may promote continuous tolerance against these specific food sources into the neonatal period. Evidence from both human and animal studies has suggested that allergic sensitization occurs during the prenatal period since the immunological environment within the uterus possibly affects the allergy development in the offspring. Several studies have also reported that a Th1 (T helper type 1 cell) response in the mother may offer the offspring protection against allergic reactions, demonstrated using a murine model and injecting non-allergic mothers with Th1 type immune inducers, such as dinitrochlorobenzene, LPS, and IFN $\gamma$ (2931). This study also shows how subjecting the offspring of allergic mothers to treatment with $\mathrm{CpG}$ oligonucleotides, a TLR9 agonist, and Th1-type stimulant, four days postnatal demonstrated protective effects against allergy development to suboptimal OVA (32). Considering the above, exposure of the allergic mother or offspring to a Th1 stimulus may help prevent an exaggerated immune response to a given allergen.

\section{INFANT IMMUNITY}

The pregnancy stage offers the fetus an immunologic environment that is highly influenced by the maternal immune system. During the neonatal period, immune responses are more often allergic Th2 reactions rather than the protective Th1 response $(33,34)$. Despite the significant role of the mother, placental tissue also contains paternal antigens with a cellular composition different than their maternal counterparts. The Th1 responses elicited due to the cellular differences may put the developing baby at risk for possible rejection by the maternal immune system. The fetal environment bypasses this issue by developing a predominantly Th2 environment to suppress the mother's Th1 response, stimulating the secretion of more Th2type cytokines and less Th1-type cytokines. Upon maturation of the baby, the predominantly Th2 environment of the uterus switches to the protective Th1 type. However, this does not occur in atopic babies, where the Th2 response continues to predominate and sets the stage for allergen sensitization and subsequent allergic responses (35).

\section{ROLE OF BREASTFEEDING}

As an ideal, nutritional, immunologic, and physiologic nourishment, breast milk and the act of breastfeeding could enhance the newborn's natural defenses to promote maturation of their immune system by increasing the levels of IgA, cytokines and probiotics (36). Within the human colostrum, $90 \%$ of all antibodies are secretory IgA that protects the infant's mucosal surfaces until the infant produces adequate quantities of self IgA. Based on careful meta-analyses on evidence surrounding the role of breast milk in well-being promotion during infancy, The European Society of Pediatric Allergy and Clinical Immunology (ESPACI) and The European Society for Pediatric Gastroenterology Hepatology and Nutrition (ESPGHAN) strongly recommend exclusive breastfeeding for 4-6 months. Similarly, The American Academy of Pediatrics (AAP) recommends breastfeeding for at least four months and introducing complementary food items no earlier than 4-6 months for optimal allergy prevention (37).

Still, the preventative effects of breastfeeding against allergic disease development during infancy remain controversial since the nature of breastfeeding is highly influenced by maternal conditions during that period. The evidence suggests that breastfeeding can offer protective measures against food allergies when the mother is non-atopic. However, breastfeeding infants of atopic mothers may put them at higher risk of developing allergies (35), which can be explained by the higher levels of cytokines and chemokines and lower levels of transforming growth factor (TGF)- $\beta 1$ in the breast milk of atopic mothers. Since TGF- $\beta 1$ promotes food tolerance in the intestinal immune response, a healthy level present in the mother's colostrum and breast milk would logically facilitate tolerance against various food allergens encountered by the infant from breastfeeding to ingestion of formula milk and solids. Nonetheless, conflicting studies still exist. Some researchers suggest that exclusive breastfeeding 
should be encouraged for at least 4 to 6 months in infants at both high and minimal risk for atopy and irrespective of a history of maternal allergy $(38,39)$.

Overall, conclusive evidence regarding either the protective or adverse effects of breastfeeding on food allergy onset is currently unavailable. Further research is required to ascertain whether breastfeeding has a positive or negative effect on the offspring's development of atopic diseases.

\section{ALLERGEN EXPOSURE DURING PREGNANCY AND LACTATION}

The scientific community widely studied and debated the role of allergen exposure during pregnancy and lactation in allergy prevention. The method of allergen detection in the amniotic fluid and breast milk can provide insight into whether allergens from the mother's diet can gain access to the developing baby and stimulate allergic sensitization $(40,41)$.

Previously, the American Academy of Pediatrics (2000) and the United Kingdom government (1998) recommended that atopic pregnant and breastfeeding mothers and their infants should avoid peanuts (42). However, no quantitative evidence suggests the fetal immune system is primed to respond to peanut allergens. Some authorities suggested the opposite: exposure to food antigens in utero may promote fetal tolerance (43) since the immune system can self-learn to distinguish between foreign or safe antigens to prevent initiating defensive action upon exposure to previously encountered items.

In 2008, the American Academy of Pediatrics withdrew its recommendations regarding the avoidance of specific food allergens (37), which was confirmed by the results of subsequent studies (44). Data taken from the Danish National Birth Cohort found that maternal peanut and tree nut intake during pregnancy played no significant role in the allergic outcomes of children at 18 months and seven years of age (45). Several recent studies also suggest the introduction of specific food allergens early on to enhance tolerance and prevent future allergic reactions. A study from 2014 reported that a higher maternal intake of peanut, milk, and wheat during early pregnancy could reduce the probability of mid-childhood allergy and asthma in the offspring (46). Similarly, the Learning Early about Peanut Allergy (LEAP) study assessed oral tolerance induction of peanut in high-risk children (with severe eczema, egg allergy, or both) aged between 4 and 11 months in the UK. Results showed that early introduction and regular ongoing consumption of peanut (average of $6 \mathrm{~g}$ of peanut protein a week) significantly decreased the frequency of peanut allergy among children already at considerable risk for developing this condition and, at the same time, modulated immune responses to peanuts (47). Even among mothers without peanut or tree (P/TN) allergy, higher pre-pregnancy consumption of $\mathrm{P} / \mathrm{TN}$ was associated with a lower risk of P/TN allergy in their offspring (48), highlighting the beneficial effects of allergen exposure during pregnancy and lactation in food allergy expression. As reviewed above, maternal dietary exposure during pregnancy and lactation will unlikely contribute to food allergy development in children and may even help prevent them.

\section{INFLUENCE OF MATERNAL GENOTYPE}

Although genetic risk factors would unlikely account for the recent spike in food allergy prevalence, they certainly play a role in one's genetic predisposition for allergy and other atopic disease development. Today, researchers can consistently identify and replicate genetic loci associated with food allergies, such as the common STAT6, IL-10, CD14, IL-12 receptor b1, IL4, TLR9, and FLG (49-53). Another large-scale genome-wide association study (GWAS) demonstrated a specific association between two allelic groups of the HLA-DQB1 gene (DQB1*02 and DQB1 ${ }^{\star} 06: 03 \mathrm{P}$ ) and peanut allergy (54). Still, we should note that previous genetic studies have mainly focused on individual genotypes without consideration for maternal influence during pregnancy and parental origins, which is why the aspect remains primarily unknown. A recent 2018 study represents the first attempt to examine maternal genotypic effects on food allergy by analyzing GWAS data generated from the Chicago Food Allergy Study. It was able to identify one single nucleotide polymorphism (rs4235235), located in a strand of non-coding RNA (LOC101927947), with significant maternal effect on any food allergy. However, its specific function is mostly unknown. Furthermore, the researchers observed three suggestive loci with maternal genetic effects: one regarding any food allergy (rs976078 located in the desert region of 13q31.1) and another two regarding an egg allergy (rs1343795 and rs4572450 located in the ZNF652 gene, whose genetic variants are associated with atopic dermatitis) (55).

Both host genetic susceptibility and environmental factors influence the complexity of food allergies (9). Studies regarding the complex gene-environment interaction effects on the intrauterine environment and, subsequently, fetal development requires further exploration.

\section{MATERNAL MICROBIOTA}

Despite the assumption that the fetal gut is sterile, recent evidence points to pregnancy as the beginning of bacterial exposure for the developing fetus upon identification of low bacterial levels in fetal membranes, meconium, amniotic fluid, and placenta (56-58). Such findings indicate the possibility of mother-to-fetus efflux of commensal bacteria through the placental barrier, breaking the sterility of the fetal gut. Considering this, the presence of bacteria or bacterial components during pregnancy may contribute to the immunological stimulatory, protective, or depletory effects for the neonate. Several researchers used animal models to demonstrate further the influence of maternal gut microbiota on offspring immunity and intestine microbiota $(59,60)$.

David Strachan proposed the hygiene hypothesis in 1989 (61) and was further substantiated and extended by studies. Due to the 
importance of bacterial colonization in healthy intestinal mucosal development, differentiation, function, and regulation, decreased microbial exposure and subsequent Th1 response stimulation in children may contribute to the development of abnormal immune responses (62). These circumstances will ultimately increase their susceptibility to allergy, asthma, and autoimmune diseases (63). Soon after birth, a vast microbiome colonizes the infant's gut through a mother-infant microbial exchange, profoundly influencing the initial development and maturation of the neonatal microbiome (64). Common perinatal interventions, including delivery mode (cesarean-section delivery or vaginal delivery), antibiotic use, and feeding pattern (formula feeding or breastfeeding), may also contribute to the infant microbiome since maternal microbiota could transfer during pregnancy and breastfeeding. A study that orally administered a labeled Enterococcus faecium strain to pregnant mice showed low levels of the labeled strain transferred to the fetal intestine and a higher level transferred to the mammary glands (56). The allergic status of the mother could derange maternal counts of Bifidobacteria, the dominant bacteria present in breastmilk, which impacts the infant's fecal Bifidobacterium levels (65). In addition, human milk oligosaccharides (HMO), which serve as prebiotics: a food source for beneficial bacteria residing in the gut, plays numerous roles in the infant's gut (66). HMOs are protective against specific harmful pathogens due to their antimicrobial properties and preventing bacterial adhesion to the intestinal epithelium. HMOs also directly affects the epithelial and immune cells, which may subsequently affect the gut microbial composition. HMOs are produced in large diversity and abundance in human milk. These glycans are not digestible by the infant and appear to serve various functions, including prebiotic stimulation of growth of specific bacterial species. Many Bifidobacteria and Bacteroides species can transport and consume HMOs, whereas Enterobacteriaceae can consume non-HMOs, such as GOS and maltodextrin, but not intact HMOs. HMOs could influence the initial colonization of the infant's gut with Bifidobacterium and Bacteroides and the distribution of the infant's microbiome, further affecting later life (67). A careful characterization of changes in the fecal microbiota of the term infant and the ingested HMOs that pass through the intestinal tract to later appear in the infant feces confirms that, as the numbers of Bifidobacteria and Bacteroides increase in the feces, the amounts of fecal HMOs decrease, suggesting that HMOs play a significant role in shaping the microbiota of the breastfed infant (68).

In theory, fetal intestines may be exposed to commensal microbes and their products in swallowed amniotic fluid, which may therefore be an important contributor to early immune development (69). Memory CD4+ and CD8+ T cells identified towards the end of the first trimester in the human fetal gut suggested that early fetal exposure to microbial antigens may impact immunity (70). While it is not clear what the relative contribution of maternal versus fetal microbiome is to offspring immunity in response to food allergy, it is plausible that both this microbiota is critical in programming fetal immunity prior to delivery.

Despite these observations, the mechanisms underlying maternal microbiota transfer to the fetus and breastmilk remain unclear. One theory proposed that maternal dendritic cells in the Peyer's Patch can cross the paracellular space of the intestinal epithelium to take up bacteria directly from the intestinal lumen (71). If so, this approach is advantageous because dendritic cells are relatively ineffective at killing internalized organisms. Thus, they serve to help viable bacteria reach the mammary glands and placenta (72). Once in the blood circulation, maternal-derived bacteria may be transferred to the fetus via the paracellular pathway of the placental barrier (71).

\section{PREVENTION AND MANAGEMENT}

Table 1 listed the prevention and management of food allergy during prenatal and postpartum.

\section{IDENTIFICATION OF HIGH-RISK INFANTS}

Without a doubt, the identification of high-risk newborns and infants can help provide direct preventive measures. Several researchers have suggested genetic linkage markers and immunologic factors, such as elevated cord blood and infancy IgE levels, food-specific IgE, lower-interferon/interleukin-4 ratio, and elevated levels of inflammatory cells (e.g., peripheral blood and nasal eosinophils and basophils) are associated with subsequent food allergy development, which may be useful in the diagnosis of high-risk infants (73-75). However, the pattern and threshold of an immune response to food allergens vary from individual to individual. None of the symptoms related to immunologically or non-immunologically mediated allergies are pathognomonic. However, inadequate sensitivity and low predictive power limit the effectiveness of diagnostic tests, deeming them unpractical for general population screening. Instead, a careful assessment through questionnaires about the family history of both parents

TABLE 1 | Prevention and management of food allergy.

Prenatal prevention

Identify High-Risk Infants

Probiotic Intervention

Immunotherapy

Hydrolysate Formula
Index: IgE levels, food-specific IgE, lower-interferon/interleukin-4 ratio, and elevated levels of inflammatory cells (73-75) A careful assessment through questionnaires about the family history of both parents $(35,76)$

Lactobacillus GG, L. acidophilus La-5 and Bifidobacterium animalis subsp. lactis Bb-12 with inconsistent results $(77,78)$ Postpartum management

Oral immunotherapy, subcutaneous and subcutaneous immunotherapy (79-81)

Hydrolyzed formula milk with inconsistent results (82-84) 
may be an adequate solution for large-scale screening. The American Academy of Pediatrics and several European committees and organizations recommend using atopic family history to identify high-risk infants and administer appropriate interventions for allergy prevention. A documented parental or relative food allergy would increase the likelihood of food allergy development in the offspring (35). For example, research has shown that a child can experience as high as a 7 -fold increase in peanut allergy risk if he or she has a parent or sibling with the same condition (85). Therefore, infants with at least one first-degree relative (parent or sibling) with the documented allergic disease would be identified as high-risk infants (76).

\section{PROBIOTIC INTERVENTION}

In the past decade, immunomodulation has been explored as a means of atopy prevention as studies have demonstrated the role of intestinal microbiota in immunity maturation during early childhood (86). It is becoming increasingly evident that intestinal microbiota influences the development of both Th1- and Th2mediated diseases through regulatory cells and pathways, which could potentially help prevent disease-associated aberrant immune responses if adequately used for interventions (87). Several epidemiologic studies have clearly shown that reduced microbial exposure in children due to the westernized lifestyle is at the root of the increased allergy prevalence in developed countries within the last several years ("Hygiene Hypothesis"), providing further evidence regarding the role of the intestinal microbiota in allergy $(88,89)$.

In terms of intervention options, the use of probiotic therapy, which involves the use of living microorganisms in adequate amounts to help confer a health benefit on the host (90), has received increasing amounts of scientific documentation and is being evaluated as a means to encourage a Th1-predominant immune system. Therefore, an appropriate microbial stimulation following birth may prove to be essential in creating a balanced Th1/Th2 response of the immune system after skewing towards Th2-type immunity at birth $(89,91,92)$.

Lactobacilli and Bifidobacteria inhabit the intestinal flora of non-allergic infants, while allergic infants demonstrate a different microbiota composition composed of elevated levels of Coliforms and Staphylococcus aureus (93-95). A study from Finland reported positive preventative effects of Lactobacillus $G G$ against early atopic disease in high-risk children when administered prenatally to mothers (who had at least one firstdegree relative (or partner) with atopic eczema, allergic rhinitis, or asthma) and postnatally for six months to their infants (88). Furthermore, maternal probiotic (a combination of Lactobacillus rhamnosos GG, L. acidophilus La-5 and Bifidobacterium animalis subsp. lactis $B b-12)$ may be sufficient for long term reduction in the cumulative incidence of offspring's atopic dermatitis (6 year follow up) (96). Prenatal and postnatal administration of high doses of Lactobacillus rhamnosus GG seems to be the most promising approach for food allergy prevention in offspring (77). The studies mentioned above suggest that gastrointestinal microbiota promotes antiallergenic processes through 1 or a combination of the following ways: (1) inducing immune deviation towards a Th1-type of immune (93). (2) resulting in multiple mechanisms to increase TGF- $\beta$ levels, which include microbiota-induced TGF- $\beta$ production as well as enhancement of active and hence functional TGF- $\beta$ levels (97). TGF- $\beta$ plays an essential role in the suppression of T-helper-2-induced allergic inflammation and induction of oral tolerance (98). and (3) IgA production, an essential component of mucosal immune defense. Bacterial-derived antigens and short-chain fatty acids directly interact with B cells to induce IgA production through G-protein coupled receptors signaling, and possibly act indirectly through intestinal epithelial cells or dendritic cells in T-cell-dependent and -independent pathways (99). However, other studies reported conflicting results. The non-selected mothers received probiotic milk containing Lactobacillus rhamnosus GG, L. acidophilus La-5, and Bifidobacterium animalis subsp. lactis Bb12 from 36 weeks of gestation to 3 months postnatal during breastfeeding showed no effect on atopic sensitization during the child's first two years of age (78). The issue when making comparisons between studies is the vast number of variables (e.g., specific species, dosage, survival rate, duration of consumption, administered age) to take into consideration before drawing any conclusions regarding the effectiveness of probiotics on the prevention of childhood food allergies.

\section{IMMUNOTHERAPY INTERVENTION}

Various forms of immunotherapy, including oral immunotherapy (OIT) and sublingual immunotherapy (SLIT), are being more frequently used since both modalities have proven to be promising and effective in children with IgE-mediated, challenge-proven peanut allergy $(80,100-102)$. OIT involves the daily ingestion of the target allergen mixed with a food vehicle in gradually increasing doses (varying from milligrams to grams), while SLIT involves the administration of small amounts, on the scale of micrograms to milligrams, of allergen extract under the tongue. Early allergen exposure in small, controlled dosages may build tolerance and reduce adverse reactions in children with severe peanut allergies (47). A double-blind, randomized, placebocontrolled trial demonstrated that low-dose OIT is a safe and efficacious treatment option for children with IgE-mediated, challenge-proven peanut allergy (79).

Although oral immunotherapy appeared far more effective than subcutaneous immunotherapy (SCIT) as a treatment of peanut allergy, it carries a higher risk for adverse reactions, presumably due to the higher doses it utilizes when compared to SLIT $(81,102)$. Although pretreatment with SCIT before OIT led to a dramatic reduction in overall adverse events, it did not eliminate the risk of intolerable gastrointestinal symptoms, ultimately leading to the discontinuation of therapy. Therefore, it is necessary to conduct additional studies to maximize both the efficacy and tolerability of these treatment options while taking into consideration the potential use of adjuvants, modified allergens, and more extended periods of maintenance dosing. 


\section{HYDROLYSATE FORMULA INTERVENTION}

When breastfeeding is insufficient, partially hydrolyzed, or extensively hydrolyzed, formula milk is recommended as a substitute for the first four to six months of infancy to reduce early allergen exposure in those at risk for allergic diseases (103). Some researchers found that allergy prevention in the first year of life in infants with a familial risk for atopy is possible through the administration of a hydrolyzed formula milk instead of cow's milk formula as a supplement or substitute for breast milk (82, 104, 105). However, various recent studies do not recommend partially hydrolyzed whey or soy-based formula milk as a preventative measure against allergy or food intolerance in high-risk infants $(83,84,106)$. To date, evidence regarding this matter remains inconclusive. Studies have findings that support both sides of the discussion on whether hydrolysate formula is an appropriate preventative measure against food allergy development in at-risk infants. A conclusive judgment should consider various factors, such as different inclusion criteria, insufficient randomization, blinding, and poorly defined diagnostic criteria.

\section{SUMMARY}

The prevalence of food allergies has increased among infants and children, and its proneness is primarily influenced by maternal immunity, microbiota, breastfeeding, allergy exposure and

\section{REFERENCES}

1. Sicherer SH, Sampson HA. Food Allergy. J Allergy Clin Immunol (2013) 125 (2):116-25.

2. Prescott SL, Pawankar R, Allen KJ, Campbell DE, Sinn J, Fiocchi A, et al. A Global Survey of Changing Patterns of Food Allergy Burden in Children. World Allergy Organ J (2013) 6(1):21. doi: 10.1186/1939-4551-6-21

3. Wang YB, Weng JJ, Zhu CB, Ai R, Zhou JR, Wang C, et al. Allergenicity Assessment and Allergen Profile Analysis of Different Chinese Wheat Cultivars. World Allergy Organ J (2021) 14(7):100559. doi: 10.1016/ j.waojou.2021.100559

4. Zeiger RS. Food Allergen Avoidance in the Prevention of Food Allergy in Infants and Children. Pediatrics (2003) 111(6):1662-71. doi: 10.1542/ peds.111.6.1495

5. Cataldo F, Accomando S, Fragapane ML, Montaperto DSIGENP and GLNBI Working Groups on Food Intolerances. Are Food Intolerances and Allergies Increasing in Immigrant Children Coming From Developing Countries ? Pediatr Allergy Immunol (2006) 17(5):364-9. doi: 10.1111/j.1399-3038.2006.00421.x

6. Ohya Y. Current Research Gaps and Unmet Clinical Needs in Food Allergy. Allergol Int (2020) 69(1):1-2. doi: 10.1016/j.alit.2019.12.002

7. Nwaru BI, Hickstein L, Panesar SS, Roberts G, Muraro A, Sheikh A, et al. Prevalence of Common Food Allergies in Europe: A Systematic Review and Meta-Analysis. Allergy (2014) 69(8):992-1007. doi: 10.1111/all.12423

8. Mehaudy R, Parisi C, Petriz N, Eymann A, Jauregui MB, Orsi M. Prevalence of Cow's Milk Protein Allergy Among Children in a University Community Hospital. Arch Argent Pediatr (2018) 116(3):219-23. doi: 10.5546/ aap.2018.eng.219

9. Tsai HJ, Kumar R, Pongracic J, Liu X, Story R, Yu Y, et al. Familial Aggregation of Food Allergy and Sensitization to Food Allergens: A genetic factors. The large-scale population identification of high-risk infants and probiotic supplementation may help provide good prenatal intervention options. Although current postpartum management such as immunotherapy and hydrolysate formula may be advised, the scientific results from published studies remain inconsistent, limiting our ability to draw firm conclusions. With that in mind, additional research is required to further elucidate the maternal influences of proneness to develop food allergy in offspring.

\section{AUTHOR CONTRIBUTIONS}

The review was written and edited by LJ. C-WS and HS helped supervise the project. All authors provided critical feedback and helped shape the final review.

\section{FUNDING}

This work was supported by grants from the National Institutes of Health-R21 AI121997 (to HS), R21 AI144738-01A1 (to CWS) and by the Nutrition Obesity Research Center at Harvard (P30 DK040561). Chien-wen Su was supported by a Pilot Feasibility Grant from the Nutrition Obesity Research Center at Harvard (P30 DK040561). Lefei Jiao was sponsored by the China Scholarship Council and Ningbo Public Welfare Science and Technology Project (202002N3041). The funders had no role in study design, collection, analysis, or interpretation of data.

Family-Based Study. Clin Exp Allergy (2009) 39(1):101-9. doi: 10.1111/ j.1365-2222.2008.03111.x

10. Kalach N, Bellaïche M, Elias-Billon I, Dupont C. Family History of Atopy in Infants With Cow's Milk Protein Allergy: A French Population-Based Study. Arch Pediatr (2019) 26(4):226-31. doi: 10.1016/j.arcped.2019.02.014

11. Chad Z. Allergies in Children. Paediatr Child Health (2001) 6(8):555-66. doi: $10.1093 / \mathrm{pch} / 6.8 .555$

12. Koplin JJ, Allen KJ, Gurrin LC, Peters RL, Lowe AJ, Tang ML, et al. The Impact of Family History of Allergy on Risk of Food Allergy: A PopulationBased Study of Infants. Int J Environ Res Public Health (2013) 10(11):536477. doi: 10.3390/ijerph10115364

13. Bjorksten B. Genetic and Environmental Risk Factors for the Development of Food Allergy. Curr Opin Allergy Clin Immunol (2005) 5(3):249-53. doi: 10.1097/01.all.0000168790.82206.17

14. Pierau M, Arra A, Brunner-Weinzierl MC. Preventing Atopic Diseases During Childhood -Early Exposure Matters. Front Immunol (2021) 12:617731. doi: 10.3389/fimmu.2021.617731

15. Burks AW, Tang M, Sicherer S, Muraro A, Eigenmann PA, Ebisawa M, et al. ICON: Food Allergy. J Allergy Clin Immunol (2012) 129(4):906-20. doi: 10.1016/j.jaci.2012.02.001

16. Sabença C, Ribeiro M, de Sousa T, Poeta P, Bagulho AS, Igrejas G. Wheat/ gluten-Telated Disorders and Gluten-Gree Diet Misconceptions: A Review. Foods (2021) 10(8):1765. doi: 10.3390/foods10081765

17. Iweala OI, Choudhary SK, Commins SP. Food Allergy. Curr Gastroenterol Rep (2018) 20:17. doi: 10.1007/s11894-018-0624-y

18. Sicherer SH, Sampson HA. Food Allergy: A Review and Update on Epidemiology, Pathogenesis, Diagnosis, Prevention, and Management. J Allergy Clin Immunol (2018) 141(1):41-58. doi: 10.1016/j.jaci.2017.11.003

19. Lyons SA, Clausen M, Knulst AC, Ballmer-Weber BK, Fernandez-Rivas M, Barreales L, et al. Prevalence of Food Sensitization and Food Allergy in 
Children Across Europe. J Allergy Clin Immunol Pract (2020) 8(8):2736-46. doi: $10.1016 /$ j.jaip.2020.04.020

20. Ferreira F, Hawranek T, Gruber P, Wopfner N, Mari A. Allergic CrossReactivity: From Gene to the Clinic. Allergy (2004) 59(3):243-67. doi: 10.1046/j.1398-9995.2003.00407.x

21. Gargano D, Appanna R, Santonicola A, De Bartolomeis F, Stellato C, Cianferoni A, et al. Food Allergy and Intolerance: A Narrative Review on Nutritional Concerns. Nutrients (2021) 13:1638. doi: 10.3390/nu13051638

22. Marcus N, Amir AZ, Grunebaum E, Dipchand A, Hebert D, Ng VL, et al. De Novo Allergy and Immune-Mediated Disorders Following Solid-Organ Transplantation-Prevalence, Natural History, and Risk Factors. J Pediatr (2018) 196:154-60. doi: 10.1016/j.jpeds.2017.11.026

23. Cianferoni A. Non-IgE Mediated Food Allergy. Curr Pediatr Rev (2020) 16 (2):95-105. doi: 10.2174/1573396315666191031103714

24. Simister NE, Story CM. Human Placental Fc Receptors and the Transmission of Antibodies From Mother to Fetus. J Reprod Immunol (1997) 37(1):1-23. doi: 10.1016/S0165-0378(97)00068-5

25. Simister NE. Placental Transport of Immunoglobulin G. Vaccine (2003) 21 (24):3365-9. doi: 10.1016/S0264-410X(03)00334-7

26. Palmeira P, Quinello C, Silveira-Lessa AL, Zago CA, Carneiro-Sampaio M. IgG Placental Transfer in Healthy and Pathological Pregnancies. Clin Dev Immunol (2012) 2012:985646. doi: 10.1155/2012/985646

27. Geroldinger-Simic M, Zelniker T, Aberer W, Ebner C, Egger C, Greiderer A, et al. Birch Pollen-Related Food Allergy: Clinical Aspects and the Role of Allergen-Specific IgE and IgG4 Antibodies. J Allergy Clin Immunol (2011) 127(3):616-622 e611. doi: 10.1016/j.jaci.2010.10.027

28. Ohsaki A, Venturelli N, Buccigrosso TM, Osganian SK, Lee J, Blumberg RS, et al. Allergen-Specific Tolerance in Offspring. J Exp Med (2017) 215(1):911135. doi: $10.1084 /$ jem. 20171163

29. Lima C, Souza VM, Faquim-Mauro EL, Hoshida MS, Bevilacqua E, Macedo MS, et al. Modulation of the Induction of Lung and Airway Allergy in the Offspring of IFN-Gamma-Treated Mother Mice. J Immunol (2005) 175 (6):3554-9. doi: 10.4049/jimmunol.175.6.3554

30. Gerhold K, Avagyan A, Seib C, Frei R, Steinle J, Ahrens B, et al. Prenatal Initiation of Endotoxin Airway Exposure Prevents Subsequent AllergenInduced Sensitization and Airway Inflammation in Mice. J Allergy Clin Immunol (2006) 118(3):666-73. doi: 10.1016/j.jaci.2006.05.022

31. Lim RH, Arredouani MS, Fedulov A, Kobzik L, Hubeau C. Maternal Allergic Contact Dermatitis Causes Increased Asthma Risk in Offspring. Respir Res (2007) 8:56. doi: 10.1186/1465-9921-8-56

32. Fedulov A, Silverman E, Xiang Y, Leme A, Kobzik L. Immunostimulatory CpG Oligonucleotides Abrogate Allergic Susceptibility in a Murine Model of Maternal Asthma Transmission. J Immunol (2005) 175(7):4292-300. doi: 10.4049/jimmunol.175.7.4292

33. Abrahamsson TR, Sandberg Abelius M, Forsberg A, Bjorksten B, Jenmalm MC. A Th1/Th2-Associated Chemokine Imbalance During Infancy in Children Developing Eczema, Wheeze and Sensitization. Clin Exp Allergy (2011) 41(12):1729-39. doi: 10.1111/j.1365-2222.2011.03827.x

34. Saini V, Arora S, Yadav A, Bhattacharjee J. Cytokines in Recurrent Pregnancy Loss. Clin Chim Acta (2011) 412(9-10):702-8. doi: 10.1016/ j.cca.2011.01.002

35. Joneja JM. Infant Food Allergy: Where are We Now? JPEN J Parenter Enteral Nutr (2012) 36(1 Suppl):49S-55S. doi: 10.1177/0148607111420155

36. Järvinen KM, Martin H, Oyoshi MK. Immunomodulatory Effects of Breast Milk on Food Allergy. Ann Allergy Asthma Immunol (2019) 123:133-43. doi: 10.1016/j.anai.2019.04.022

37. Greer FR, Sicherer SH, Burks AWAmerican Academy of Pediatrics Committee on Nutritions and American Academy of Pediatrics Section on Allergy and Immunology. Effects of Early Nutritional Interventions on the Development of Atopic Disease in Infants and Children: The Role of Maternal Dietary Restriction, Breastfeeding, Timing of Introduction of Complementary Foods, and Hydrolyzed Formulas. Pediatrics (2008) 121 (1):183-91. doi: 10.1542/peds.2007-3022

38. Friedman NJ, Zeiger RS. The Role of Breast-Feeding in the Development of Allergies and Asthma. J Allergy Clin Immunol (2005) 115(6):1238-48. doi: 10.1016/j.jaci.2005.01.069

39. Blixt I, Johansson M, Hildingsson I, Papoutsi Z, Rubertsson C. Women's Advice to Healthcare Professionals Regarding Breastfeeding: "Offer Sensitive
Individualized Breastfeeding Support"- an Interview Study. Int Breastfeed J (2019) 14:51. doi: 10.1186/s13006-019-0247-4

40. Szepfalusi Z, Loibichler C, Pichler J, Reisenberger K, Ebner C, Urbanek R. Direct Evidence for Transplacental Allergen Transfer. Pediatr Res (2000) 48 (3):404-7. doi: 10.1203/00006450-200009000-00024

41. Han P, Gu JQ, Li LS, Wang XY, Wang HT, Wang Y, et al. The Association Between Intestinal Bacteria and Allergic Diseases-Cause or Consequence? Front Cell Infect Microbiol (2021) 11:650893. doi: 10.3389/ fcimb.2021.650893

42. Hourihane JO, Aiken R, Briggs R, Gudgeon LA, Grimshaw KE, DunnGalvin A, et al. The Impact of Government Advice to Pregnant Mothers Regarding Peanut Avoidance on the Prevalence of Peanut Allergy in United Kingdom Children at School Entry. J Allergy Clin Immunol (2007) 119(5):1197-202. doi: 10.1016/j.jaci.2006.12.670

43. Calvani M, Alessandri C, Sopo SM, Panetta V, Pingitore G, Tripodi S, et al. Consumption of Fish, Butter and Margarine During Pregnancy and Development of Allergic Sensitizations in the Offspring: Role of Maternal Atopy. Pediatr Allergy Immunol (2006) 17(2):94-102. doi: 10.1111/j.13993038.2005.00367.x

44. Garcia-Larsen V, Ierodiakonou D, Jarrold K, Cunha S, Chivinge J, Robinson Z, et al. Diet During Pregnancy and Infancy and Risk of Allergic or Autoimmune Disease: A Systematic Review and Meta-Analysis. PloS Med (2018) 15(2):e1002507. doi: 10.1371/journal.pmed.1002507

45. Maslova E, Granstrom C, Hansen S, Petersen SB, Strom M, Willett WC, et al. Peanut and Tree Nut Consumption During Pregnancy and Allergic Disease in Children-Should Mothers Decrease Their Intake? Longitudinal Evidence From the Danish National Birth Cohort. J Allergy Clin Immunol (2012) 130 (3):724-32. doi: 10.1016/j.jaci.2012.05.014

46. Bunyavanich S, Rifas-Shiman SL, Platts-Mills TA, Workman L, Sordillo JE, Camargo CAJr., et al. Peanut, Milk, and Wheat Intake During Pregnancy is Associated With Reduced Allergy and Asthma in Children. J Allergy Clin Immunol (2014) 133(5):1373-82. doi: 10.1016/j.jaci.2013.11.040

47. Du Toit G, Roberts G, Sayre PH, Bahnson HT, Radulovic S, Santos AF, et al. Randomized Trial of Peanut Consumption in Infants at Risk for Peanut Allergy. N Engl J Med (2015) 372(9):803-13. doi: 10.1056/NEJMoa1414850

48. Frazier AL, Camargo CAJr., Malspeis S, Willett WC, Young MC. Prospective Study of Peripregnancy Consumption of Peanuts or Tree Nuts by Mothers and the Risk of Peanut or Tree Nut Allergy in Their Offspring. JAMA Pediatr (2014) 168(2):156-62. doi: 10.1001/jamapediatrics.2013.4139

49. Amoli MM, Hand S, Hajeer AH, Jones KP, Rolf S, Sting C, et al. Polymorphism in the STAT6 Gene Encodes Risk for Nut Allergy. Genes Immun (2002) 3(4):220-4. doi: 10.1038/sj.gene.6363872

50. Campos Alberto EJ, Shimojo N, Suzuki Y, Mashimo Y, Arima T, Matsuura T, et al. IL-10 Gene Polymorphism, But Not TGF-Betal Gene Polymorphisms, Is Associated With Food Allergy in a Japanese Population. Pediatr Allergy Immunol (2008) 19(8):716-21. doi: 10.1111/ j.1399-3038.2007.00709.x

51. Brown SJ, Asai Y, Cordell HJ, Campbell LE, Zhao Y, Liao H, et al. Loss-OfFunction Variants in the Filaggrin Gene Are a Significant Risk Factor for Peanut Allergy. J Allergy Clin Immunol (2011) 127(3):661-7. doi: 10.1016/ j.jaci.2011.01.031

52. Dreskin SC, Ayars A, Jin Y, Atkins D, Leo HL, Song B. Association of Genetic Variants of CD14 With Peanut Allergy and Elevated IgE Levels in Peanut Allergic Individuals. Ann Allergy Asthma Immunol (2011) 106 (2):170-2. doi: 10.1016/j.anai.2010.11.008

53. Xie J, Lotoski LC, Chooniedass R, Su RC, Simons FE, Liem J, et al. Elevated Antigen-Driven IL-9 Responses are Prominent in Peanut Allergic Humans. PloS One (2012) 7(10):e45377. doi: 10.1371/journal.pone.0045377

54. Madore AM, Vaillancourt VT, Asai Y, Alizadehfar R, Ben-Shoshan M, Michel DL, et al. HLA-DQB1 ${ }^{*} 02$ and $\mathrm{DQB1} 1^{*} 06: 03 \mathrm{P}$ Are Associated With Peanut Allergy. Eur J Hum Genet (2013) 21(10):1181-4. doi: 10.1038/ ejhg.2013.13

55. Liu X, Hong X, Tsai HJ, Mestan KK, Shi M, Kefi A, et al. Genome-Wide Association Study of Maternal Genetic Effects and Parent-of-Origin Effects on Food Allergy. Medicine (Baltimore) (2018) 97(9):e0043. doi: 10.1097/ MD.0000000000010043

56. Jimenez E, Fernandez L, Marin ML, Martin R, Odriozola JM, Nueno-Palop C, et al. Isolation of Commensal Bacteria From Umbilical Cord Blood of 
Healthy Neonates Born by Cesarean Section. Curr Microbiol (2005) 51 (4):270-4. doi: 10.1007/s00284-005-0020-3

57. Han YW, Ikegami A, Bissada NF, Herbst M, Redline RW, Ashmead GG. Transmission of an Uncultivated Bergeyella Strain From the Oral Cavity to Amniotic Fluid in a Case of Preterm Birth. J Clin Microbiol (2006) 44 (4):1475-83. doi: 10.1128/JCM.44.4.1475-1483.2006

58. Aagaard K, Ma J, Antony KM, Ganu R, Petrosino J, Versalovic J. The Placenta Harbors a Unique Microbiome. Sci Transl Med (2014) 6 (237):237ra265. doi: 10.1126/scitranslmed.3008599

59. Ganal-Vonarburg SC, de Aguero MG, Fuhrer T, Sauer U, McCoy KD, Macpherson AJ. The Maternal Microbiota Drives Early Postnatal Innate Immune Development. Swiss Med Wkly (2016) 146:7S-S. doi: 10.1126/ science.aad 2571

60. Nyangahu DD, Lennard KS, Brown BP, Darby MG, Wendoh JM, Havyarimana E, et al. Disruption of Maternal Gut Microbiota During Gestation Alters Offspring Microbiota and Immunity. Microbiome (2018) 6(1):124. doi: 10.1186/s40168-018-0511-7

61. Strachan DP. Hay Fever, Hygiene and Household Size. Br Med J (1989) 299:1259-60. doi: 10.1136/bmj.299.6710.1259

62. Apostol AC, Jensen KDC, Beaudin AE. Training the Fetal Immune System Through Maternal Inflammation-A Layered Hygiene Hypothesis. Front Immunol (2020) 11:123. doi: 10.3389/fimmu.2020.00123

63. Romagnani S. The Increased Prevalence of Allergy and the Hygiene Hypothesis: Missing Immune Deviation, Reduced Immune Suppression, or Both? Immunology (2004) 112(3):352-63. doi: 10.1111/j.13652567.2004.01925.x

64. Mueller NT, Bakacs E, Combellick J, Grigoryan Z, Dominguez-Bello MG. The Infant Microbiome Development: Mom Matters. Trends Mol Med (2015) 21(2):109-17. doi: 10.1016/j.molmed.2014.12.002

65. Gronlund MM, Gueimonde M, Laitinen K, Kociubinski G, Gronroos T, Salminen S, et al. Maternal Breast-Milk and Intestinal Bifidobacteria Guide the Compositional Development of the Bifidobacterium Microbiota in Infants at Risk of Allergic Disease. Clin Exp Allergy (2007) 37(12):176472. doi: $10.1111 / j .1365-2222.2007 .02849 . x$

66. Moossavi S, Miliku K, Sepehri S, Khafipour E, Azad MB. The Prebiotic and Probiotic Properties of Human Milk: Implications for Infant Immune Development and Pediatric Asthma. Front Pediatr (2018) 24;6:197. doi: $10.3389 /$ fped.2018.00197

67. Gopalakrishna KP, Hand TW. Influence of Maternal Milk on the Neonatal Intestinal Microbiome. Nutrients (2020) 12(3):823. doi: 10.3390/ nu12030823

68. Sohn K, Underwood MA. Prenatal and Postnatal Administration of Prebiotics and Probiotics. Semin Fetal Neonatal Med (2017) 22(5):284-9. doi: 10.1016/j.siny.2017.07.002

69. Nyangahu DD, Jaspan HB. Influence of Maternal Microbiota During Pregnancy on Infant Immunity. Clin Exp Immunol (2019) 198(1). doi: $10.1111 /$ cei.13331

70. Li N, van Unen V, Abdelaal T, Guo N, Kasatskaya SA, Ladell K, et al. Memory CD4+ T Cells Are Generated in the Human Fetal Intestine. Nat Immunol (2019) 20:301-12. doi: 10.1038/s41590-018-0294-9

71. Thum C, Cookson AL, Otter DE, McNabb WC, Hodgkinson AJ, Dyer J, et al. Can Nutritional Modulation of Maternal Intestinal Microbiota Influence the Development of the Infant Gastrointestinal Tract? J Nutr (2012) 142 (11):1921-8. doi: 10.3945/jn.112.166231

72. Donnet-Hughes A, Perez PF, Dore J, Leclerc M, Levenez F, Benyacoub J, et al. Potential Role of the Intestinal Microbiota of the Mother in Neonatal Immune Education. Proc Nutr Soc (2010) 69(3):407-15. doi: 10.1017/ S0029665110001898

73. Kaan A, Dimich-Ward H, Manfreda J, Becker A, Watson W, Ferguson A, et al. Cord Blood IgE: Its Determinants and Prediction of Development of Asthma and Other Allergic Disorders at 12 Months. Ann Allergy Asthma Immunol (2000) 84(1):37-42. doi: 10.1016/S1081-1206(10)62738-X

74. Sampson HA. Utility of Food-Specific IgE Concentrations in Predicting Symptomatic Food Allergy. J Allergy Clin Immunol (2001) 107(5):891-6. doi: $10.1067 /$ mai.2001.114708

75. Stone KD, Prussin C, Metcalfe DD. IgE, Mast Cells, Basophils, and Eosinophils. J Allergy Clin Immunol (2010) 125(2 Suppl 2):S73-80. doi: 10.1016/j.jaci.2009.11.017
76. Ghaffari J, Ghaffari N. Dietary Primary Prevention of Allergic Disease: A Review. J Pediatr Rev (2019) 7(5):7-7.

77. Cosenza L, Nocerino R, Di Scala C, di Costanzo M, Amoroso A, Leone L, et al. Bugs for Atopy: The Lactobacillus Rhamnosus GG Strategy for Food Allergy Prevention and Treatment in Children. Benef Microbes (2015) 6 (2):225-32. doi: 10.3920/bm2014.0158

78. Dotterud CK, Storro O, Johnsen R, Oien T. Probiotics in Pregnant Women to Prevent Allergic Disease: A Randomized, Double-Blind Trial. $\mathrm{Br} J$ Dermatol (2010) 163(3):616-23. doi: 10.1111/j.1365-2133.2010.09889.x

79. Bird JA, Spergel JM, Jones SM, Rachid R, Assa'ad AH, Wang J, et al. Efficacy and Safety of AR101 in Oral Immunotherapy for Peanut Allergy: Results of ARC001, a Randomized, Double-Blind, Placebo-Controlled Phase 2 Clinical Trial. J Allergy Clin Immunol Pract (2018) 6(2):476-485.e473. doi: 10.1016/ j.jaip.2017.09.016

80. Blumchen K, Trendelenburg V, Ahrens F, Gruebl A, Hamelmann E, Hansen G, et al. Efficacy, Safety, and Quality of Life in a Multicenter, Randomized, Placebo-Controlled Trial of Low-Dose Peanut Oral Immunotherapy in Children With Peanut Allergy. J Allergy Clin Immunol In Pract (2019) 7 (2):479-491.e410. doi: 10.1016/j.jaip.2018.10.048

81. Johnson-Weaver BT, Staats HF, Burks AW, Kulis MD. Adjuvanted Immunotherapy Approaches for Peanut Allergy. Front Immunol (2018) 25:2156(9). doi: 10.3389/fimmu.2018.02156

82. Kansu A, Yüce A, Dalg B, Sekerel BE, Cullu-Cokugras FC, Cokugras H. Consensus Statement on Diagnosis, Treatment and Follow-Up of Cow's Milk Protein Allergy Among Infants and Children in Turkey. Turk J Pediatr (2016) 58(1):1-11. doi: 10.24953/turkjped.2016.01.001

83. Brand PL. Partially Hydrolysed Whey and Soy-Based Infant Formulas did Not Prevent Allergic Disease in High-Risk Children. Arch Dis Child Educ Pract Ed (2012) 97(3):120. doi: 10.1136/archdischild-2011-300992

84. Ferraro V, Zanconato S, Carraro S. Timing of Food Introduction and the Risk of Food Allergy. Nutrients (2019) 11:1131. doi: 10.3390/nu11051131

85. Hourihane JO, Dean TP, Warner JO. Peanut Allergy in Relation to Heredity, Maternal Diet, and Other Atopic Diseases: Results of a Questionnaire Survey, Skin Prick Testing, and Food Challenges. BMJ (1996) 313 (7056):518-21. doi: 10.1136/bmj.313.7056.518

86. Kreft L, Hoffmann C, Ohnmacht C. Therapeutic Potential of the Intestinal Microbiota for Immunomodulation of Food Allergies. Front Immunol (2020) 11:1853. doi: 10.3389/fimmu.2020.01853

87. Kaplan JL, Shi HN, Walker WA. The Role of Microbes in Developmental Immunologic Programming. Pediatr Res (2011) 69(6):465-72. doi: 10.1203/ PDR.0b013e318217638a

88. Kalliomaki M, Salminen S, Arvilommi H, Kero P, Koskinen P, Isolauri E. Probiotics in Primary Prevention of Atopic Disease: A Randomised PlaceboControlled Trial. Lancet (2001) 357(9262):1076-9. doi: 10.1016/S0140-6736 (00)04259-8

89. Romagnani S. Immunologic Influences on Allergy and the TH1/TH2 Balance. J Allergy Clin Immunol (2004) 113(3):395-400. doi: 10.1016/ j.jaci.2003.11.025

90. Sanders ME. Probiotics: Definition, Sources, Selection, and Uses. Clin Infect Dis (2008) 46 Suppl. doi: 10.1086/523341

91. Furrie E. Probiotics and Allergy. Proc Nutr Soc (2005) 64(4):465-9. doi: $10.1079 / \mathrm{PNS} 2005466$

92. Strzępa A, Lobo FM, Majewska-Szczepanik M, Szczepanik M. Antibiotics and Autoimmune and Allergy Diseases: Causative Factor or Treatment? Int Immunopharmacol (2018) 65:328-41. doi: 10.1016/j.intimp.2018.10.021

93. Bjorksten B, Naaber P, Sepp E, Mikelsaar M. The Intestinal Microflora in Allergic Estonian and Swedish 2-Year-Old Children. Clin Exp Allergy (1999) 29(3):342-6. doi: 10.1046/j.1365-2222.1999.00560.x

94. Bottcher MF, Nordin EK, Sandin A, Midtvedt T, Bjorksten B. MicrofloraAssociated Characteristics in Faeces From Allergic and Nonallergic Infants. Clin Exp Allergy (2000) 30(11):1590-6. doi: 10.1046/j.13652222.2000.00982.x

95. Kuitunen M, Kukkonen K, Juntunen-Backman K, Korpela R, Poussa T, Tuure T, et al. Probiotics Prevent IgE-Associated Allergy Until Age 5 Years in Cesarean-Delivered Children But Not in the Total Cohort. J Allergy Clin Immunol (2009) 123(2):335-41. doi: 10.1016/j.jaci.2008.11.019

96. Simpson MR, Dotterud CK, Storrø O, Johnsen R, Øien T. Perinatal Probiotic Supplementation in the Prevention of Allergy Related Disease: 6 Year Follow 
Up of a Randomised Controlled Trial. BMC Dermatol (2015) 15:13. doi: 10.1186/s12895-015-0030-1

97. Bauché D, Marie JC. Transforming Growth Factor $\beta$ : A Master Regulator of the Gut Microbiota and Immune Cell Interaction. Clin Transl Immunol (2017) 6(4):e136. doi: 10.1038/cti.2017.9

98. Michael H, Li Y, Wang Y, Xue D, Shan J, Mazer BD, et al. TGF- $\beta$-Mediated Airway Tolerance to Allergens Induced by Peptide-Based Immunomodulatory Mucosal Vaccination. Mucosal Immunol (2015) 8:1248-61. doi: 10.1038/mi.2015.15

99. Campbell E, Hesser LA, Nagler CR. B Cells and the Microbiota: A Missing Connection in Food Allergy. Mucosal Immunol (2021) 14:4-13. doi: 10.1038/s41385-020-00350-x

100. Blumchen K, Ulbricht H, Staden U, Dobberstein K, Beschorner J, de Oliveira LCL, et al. Oral Peanut Immunotherapy in Children With Peanut Anaphylaxis. J Allergy Clin Immunol (2010) 126(1):83-91.e81. doi: 10.1016/j.jaci.2010.04.030

101. Kim EH, Bird JA, Kulis M, Laubach S, Pons L, Shreffler W, et al. Sublingual Immunotherapy for Peanut Allergy: Clinical and Immunologic Evidence of Desensitization. J Allergy Clin Immunol (2011) 127(3):640-646.e641. doi: 10.1016/j.jaci.2010.12.1083

102. Narisety SD, Frischmeyer-Guerrerio PA, Keet CA, Gorelik M, Schroeder J, Hamilton RG, et al. A Randomized, Double-Blind, Placebo-Controlled Pilot Study of Sublingual Versus Oral Immunotherapy for the Treatment of Peanut Allergy. J Allergy Clin Immunol (2015) 135(5):1275-1282.e1826. doi: $10.1016 /$ j.jaci.2014.11.005

103. Fleischer DM, Spergel JM, Assaad AH, Pongracic JA. Primary Prevention of Allergic Disease Through Nutritional Interventions. J Allergy Clin Immunol Pract (2013) 1(1):29-36. doi: 10.1016/j.jaip.2012.09.003

104. Chandra RK. Five-Year Follow-Up of High-Risk Infants With Family History of Allergy Who Were Exclusively Breast-Fed or Fed Partial Whey Hydrolysate, Soy, and Conventional Cow's Milk Formulas. J Pediatr
Gastroenterol Nutr (1997) 24(4):380-8. doi: 10.1097/00005176-19970400000005

105. von Berg A, Koletzko S, Grubl A, Filipiak-Pittroff B, Wichmann HE, Bauer CP, et al. The Effect of Hydrolyzed Cow's Milk Formula for Allergy Prevention in the First Year of Life: The German Infant Nutritional Intervention Study, a Randomized Double-Blind Trial. J Allergy Clin Immunol (2003) 111(3):533-40. doi: 10.1067/mai.2003.101

106. Lowe AJ, Hosking CS, Bennett CM, Allen KJ, Axelrad C, Carlin JB, et al. Effect of a Partially Hydrolyzed Whey Infant Formula at Weaning on Risk of Allergic Disease in High-Risk Children: A Randomized Controlled Trial. J Allergy Clin Immunol (2011) 128(2):360-365 e364. doi: 10.1016/ j.jaci.2010.05.006

Conflict of Interest: The authors declare that the research was conducted in the absence of any commercial or financial relationships that could be construed as a potential conflict of interest.

Publisher's Note: All claims expressed in this article are solely those of the authors and do not necessarily represent those of their affiliated organizations, or those of the publisher, the editors and the reviewers. Any product that may be evaluated in this article, or claim that may be made by its manufacturer, is not guaranteed or endorsed by the publisher.

Copyright $\odot 2022$ Jiao, Su, Cao, Zheng, Walker and Shi. This is an open-access article distributed under the terms of the Creative Commons Attribution License (CC BY). The use, distribution or reproduction in other forums is permitted, provided the original author(s) and the copyright owner(s) are credited and that the original publication in this journal is cited, in accordance with accepted academic practice. No use, distribution or reproduction is permitted which does not comply with these terms. 